\title{
The Spiritual Care Giver as a Bearer of Stories: A Belgian Exploration of the Best Possible Spiritual Care
}

\author{
Anne Vandenhoeck
}

Belgium consists of three regions, defined by the use of language: the Flemish-, French- and German-speaking regions. In what follows, I will focus on the Flemish part of Belgium as professional spiritual care is more organized and integrated in healthcare there than in the French- and German-speaking regions. This observation is based on the fact that Flanders has the highest number of paid spiritual care givers in healthcare institutions in comparison with the other regions and has a professional association for spiritual care givers. ${ }^{1}$ Professional spiritual care in Belgium is mainly provided by Roman Catholic spiritual care givers and Humanist spiritual care givers. Spiritual care givers from those two groups are hired and paid by general hospitals or other healthcare institutions, such as mental health hospitals, nursing homes or homes for people with disabilities. Healthcare institutions are by law obligated to give patients access to the support of a representative of their faith or life view. Representatives of other religions or life views are usually not staff members in hospitals, but external representatives who are called in and are paid per (requested) visit. The profile of a Catholic spiritual care giver in Belgium is no longer that of a male priest. In Flanders, the majority of Catholic spiritual care givers are lay women. The change in staff has also provided a paradigm shift in Catholic spiritual care: since the late eighties it has no longer been focused on sacraments but on narrative hermeneutical pastoral care. ${ }^{2}$ Patient and spiritual care giver both enter

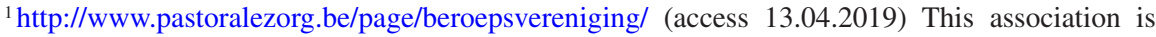
called: The Professional Association for Catholic Spiritual care givers in Health Care.

${ }^{2}$ See the works of Charles Gerkin, who reinserted a theological foundation in pastoral care after the therapeutic paradigm. His theological foundation was based on the hermeneutics of Ricœur and Gadamer, on the theology of Moltmann and Niebuhr. See for example: C.V. Gerkin, The Living Human Document: Re-Visioning Pastoral Counseling in a Hermeneutical Mode, Nashville, TN,
}

\footnotetext{
A. Vandenhoeck $(\square)$

Catholic University of Leuven, Leuven, Belgium

e-mail: anna.vandenhoeck@kuleuven.be
} 
the encounter with their own horizon of (pre-)understanding. In their meeting, the dialogue between their horizons of understanding can influence them both and lead to a new understanding, adding to the spiritual story of both patient and spiritual care giver.

For some time now there have been spiritual care givers in Flanders who chart in electronic patient files. However, this does not apply to everyone: there are spiritual care givers who have only recently received access to the electronic patient file and there are those who still have no access at all. Thus there is no uniformity regarding charting in spiritual care in Flanders. What is remarkable is the variety of visions that are at the origins of the differences: for one hospital management, it is selfevident that spiritual care givers should have access to patient files and chart, because they contribute to the care of patients. For others, spiritual care givers shouldn't have access to patient files because they are not a recognized medical or paramedical profession. Some managers or directors see spiritual care givers as non-professionals, einzelgänger who are there to convert patients to their life views. They have no clue what spiritual care givers do and don't see a reason to give them access to patient files. Spiritual care givers themselves also differ in their motivations of charting. Some are very happy to chart and to have a forum to share their care for patients and loved ones. Others are very hesitant and not convinced of the necessity to chart. Doubts regarding charting almost always have to do with confidentiality.

In this article we limit ourselves to the situation of spiritual care in general hospitals in Flanders. At the request of several Catholic spiritual care givers in general and university hospitals, an exchange group met twice in 2017 about the opportunities and tensions of electronic charting. This includes the perspective of patients, who can view their file online. The text below is partly based on the discussions at these meetings.

\section{A Lack of Uniformity Regarding Spiritual Care in Electronic Patient Files}

There is a great variety in the possibilities that spiritual care givers have regarding charting. A first determining factor in the differences is the software for the electronic patient files. Some of the developed software programs, especially those of an Anglo-Saxon design, include ample space for spiritual care and are not limited to a box for denomination and/or sacraments received. As a consequence, spiritual care is really integrated in a whole person perspective on the patient. Within this perspective, there is often less limitation in access for spiritual care givers to the charting of other healthcare professionals on the same patient. Even if the patient is transferred or admitted to a different unit than their own, spiritual care givers can obtain

Abingdon, 1984. C. V. Gerkin, Widening the Horizons. Pastoral Responses to a Fragmented Society, Philadelphia, PA, Westminster John Knox Press, 1986. 
temporary permission to access the electronic patient file, provided that this can be justified. Some hospitals develop their own software for patient files. Examples of this in Flanders are the University Hospitals of Leuven, connected with the Catholic University (KU Leuven). The design of their software provides ample space for spiritual care. ${ }^{3}$ This system is shared by all affiliated hospitals. The spiritual care givers of these hospitals formed a task force where they discussed the possibilities and limitations of the software while it was developed and put into practice. In other words: they had an input as spiritual care givers in the development of the system and the language used for their sections. The differences in charting are thus partially down to the differences in software.

But software development is also based on perceptions of healthcare. If the perspective is truly one of the whole person, not merely theoretically but in reality, then spiritual care will also be integrated in charting systems. In an important development, the University Hospitals of Leuven are currently working to develop a new interdisciplinary patient file. The current patient file is still too much based on the kind of charting that doctors and nurses do. Most systems are not designed for paramedical but for medical charting. It is not always easy to be integrated as a paramedic or as a spiritual care giver in a way that does justice to the work and the perspective of a different discipline other than the medical one. The new interdisciplinary electronic patient file will start from the importance of empowering patients, communication, working together and of a whole patient perspective. It is based on WHO's International Classification of Functioning (ICF). Spiritual care givers will have a checklist to assess the spiritual needs of patients and to communicate the outcomes of spiritual care. At the same time, they will have boxes to chart in a narrative way. The checklists for spiritual needs and outcomes are based on the model of Discipline for Pastoral Care Giving (Vandecreek and Lucas 2001), which I will discuss later in this contribution.

Spiritual care givers in Flanders try to work as well as they can with the system that is used in their hospital. They testify to the fact that they are looking for ways to make the system work as well as possible in pursuit of the best possible spiritual care. An example of this is the so-called final report within the Nexus EHR system. If a care giver makes a 'final entry' in counselling (or caring for) a patient around the time of his/her discharge, the system considers this care relationship as terminated and the care giver is not informed when the patient is re-admitted. Spiritual care givers who have to work with this system do not make a 'final entry' or report so that they are informed when the patient is re-admitted and they can visit him or her again.

As already mentioned above, a second determining factor in the lack of uniformity is the level of access spiritual care givers have to patient files. The question arises on what principles (legal and others) the hospital managements decide to allow spiritual care givers access to electronic patient files or not. There is no general rule, but it is good to know that all spiritual care givers are hired and paid by hospitals in Flanders and are technically staff members who are involved in patient

\footnotetext{
${ }^{3}$ The software for electronic charting is called KWS: Clinical Work Station.
} 
care. Moreover, quality control systems like JCI have been designed to integrate spiritual care in order to enhance the quality of patient care and facilitate charting by spiritual care givers. ${ }^{4}$ Visibility, accountability and transparency are key features in quality control.

A third determining factor in the lack of uniformity is the level of access to the charting of other professional staff in patient files. If spiritual care givers have access to patient files, they do not necessarily have access to the charting of all the other healthcare professionals (and vice versa). There seems to be no uniformity in who has access to whose charting on the patient in the different hospitals in Flanders. In one hospital, spiritual care givers have only access to the charting of the nurses and in another hospital to the charting of nurses and social workers but not, for example, to the charting of psychologists or doctors. Again, the differences in access to charting of other professional groups reflect differing perspectives on team work. A multidisciplinary take will emphasize the importance of different disciplines but not necessarily of working together for the same patient goals as an interdisciplinary approach does. Decisions about access to charting are taken according to the perspective taken.

Among the spiritual care givers themselves, there is no unity either regarding feelings or beliefs about charting. Spiritual care givers who are not allowed to chart in the electronic patient file often feel isolated. This feeling is exacerbated when they see spiritual care moving to the periphery of healthcare. There are spiritual care givers who have the opportunity to chart but deliberately choose not to or write down as little as possible or chart exclusively with document protection so that what they write is not visible to others. Their motivation rests mainly on the value of confidentiality in the spiritual care giver-patient relationship. Other spiritual care givers feel limited in their care or find that they cannot provide optimal spiritual care because they are denied access to parts of the electronic file, such as the reports of the psychologists or the doctors' follow-up papers. Lastly, there are spiritual care givers who chart out of the perception that they are professional care givers like the others and that they have to contribute to team work by means of charting. It is noteworthy that few spiritual care givers have negative feelings towards oral communication about patients with other members of staff. Naturally, charting does not exclude oral communication.

\section{Different Forms of Charting Used by Spiritual Care Givers}

In the last 10 years, Catholic spiritual care givers in Flanders have regularly committed themselves to reading articles, taking training courses and holding discussions about the challenges and possibilities of charting. A distinction has always

\footnotetext{
${ }^{4} \mathrm{JCI}$ stands for Joint Commission International. It is a US-based organization that works internationally towards improving healthcare by evaluating the quality of care provided. See https://www. jointcommission.org (Access 17.04.2019). Other international or European-based organizations aim for the same goals regarding evaluating quality of healthcare.
} 
been between charting for oneself, disciplinary charting and interdisciplinary charting. With charting for themselves, spiritual care givers refer to the notes that they make for themselves about the patient. These notes serve to record the main story lines and details from the patient's story and determine the quality of possible future spiritual care for the same patient. In this regard, spiritual care givers are bearers of stories. Disciplinary charting refers to those notes about the patient that can be useful for colleagues (spiritual care givers) when the patient needs follow-up in the absence of the spiritual care giver or when the patient is moved to another unit where another spiritual care giver works. Interdisciplinary charting refers to sharing information about the patient that can be useful to healthcare professionals from other disciplines in regard to the overall care for the patient. Every form of charting takes place in the interest of the best possible spiritual care for the patient. The answer to the question why these different forms of charting exist next to each other is quite simple: confidentiality. Spiritual care givers in Flanders often struggle with the question how much of what a patient or loved one confides in them can be shared with others.

A second difference refers to charting via a checklist or through a narrative. In a checklist, spiritual care givers tick boxes that say something about the contact with the patient with calibrated terms. This form of charting is most evident in the context of interdisciplinary charting. A second form of charting is narrative charting. Mostly in complete sentences, the spiritual care giver notes several aspects out of contact with the patient that are important for the overall care plan. There are pros and cons for both ways of charting. The experience of spiritual care givers is that checklists are not often read through. On the other hand, it is a much used tool in healthcare. It takes practice and experience to write comprehensive narrative notes without disclosing too much information and breaching confidence. It is not easy. On the other hand, it is more likely to be read.

\section{Tensions and Opportunities}

Most Flemish spiritual care givers experience the possibilities of charting as positive. The main motivation to chart in an electronic patient file is the contribution that personal, disciplinary and interdisciplinary charting can offer to the patients the best possible spiritual care. Accurate retention of important facts and storylines is a fundamental contribution to high quality and continuous spiritual care. It contributes strongly to the spiritual care giver as a bearer of stories. Colleagues of a spiritual care giver who receive sufficient background information through charting can continue or take over the care for patients during absences. Other healthcare givers who see that the spiritual care giver is involved with a patient will call more quickly when necessary. Furthermore, spiritual care givers also report that they often receive positive feedback from other care givers on what they chart and their charting makes them more visible in an interdisciplinary team. Charting is also perceived as a way of self-care. Spiritual care givers stop between visits to chart and take a break from 
visiting. They also report that charting is a way to reflect on what they have done, thus enhancing their professional skills. But in addition to the contribution to quality and efficient spiritual care and the positive side effects of better integration, spiritual care givers also experience a number of tensions and disadvantages in charting.

\subsection{Protected Files for Charting Spiritual Care}

Charting takes time - often, more than spiritual caregivers are willing to invest. That is why they are looking to use the needed time as efficiently as possible. One of the things that turns out to be an obstacle is the difference between charting for oneself and for others. Spiritual care givers are bearers of stories. Patients entrust them with their life stories. The spiritual care giver is expertly trained to see in those life stories the windows that are opened on the spiritual dimension, the meaning system that enables the patient to live as meaningfully as possible, despite the limitations of age, disease or condition. Spiritual care givers carry these stories together with the patient and connect them, if desired, with the greater spiritual stories that are important to the patient. In order to be able to remember the patient's stories, it is necessary for the spiritual care giver to record important facts and story lines. However, these are not relevant for the whole of the care or/and are often told in confidence. In other words, spiritual care givers need to keep more information on a narrative level than they want or can share with other healthcare providers. Nothing is more annoying than meeting a patient again and not remembering what he has entrusted to you during the previous visit a few months ago. That is why many spiritual care givers use the possibility to check a document marked as 'protected' in the electronic patient file. Other healthcare givers cannot open the file. However, there are hospitals that strongly discourage the creation of protected documents because of shared confidentiality in the context of interdisciplinary care or whole person care. They then ask what the value of an electronic patient file if a part of the information is not shared. Does it still show a multi-dimensional image of the patient? But if protected documents are not possible, should the pastor chart separately in notebooks, index cards or word documents outside the electronic file and do double work?

\subsection{The Tension Between Being Sent by a Faith Community and Being Hired by a Hospital}

The tension between being sent by a faith community and being hired by a hospital is increased by charting in the electronic patient file. It is the tension of being affiliated with a tradition that evokes trust and confidentiality and being a professional care giver paid by the hospital. What can you chart and for whom? These are questions that arise in the context of the trust that the patient places in spiritual care givers. Supporters of charting will state that patients know that every healthcare 
provider is part of a team and that it is necessary to communicate in order to coordinate the care as well as possible. Good care means shared and coordinated care. Critics will argue that the patient often sees the spiritual care giver as an outsider, someone who does not really belong to the team and whom you can trust. That trust has not only to do with the eccentric place in the care team but also with the background of spiritual care giving. Catholic spiritual care givers suspect that the ecclesiastical tradition of the confessional confidentiality, which is absolute and of the altar as a sanctuary, still plays a role in the perception of the spiritual care giver. In other words, patients have an archaic image of the spiritual care giver as a confidential advisor par excellence. This image is passed on from generation to generation regardless of whether patients are Catholic or not and regardless of secularization. Spiritual care givers notice this image with patients of all ages and life views. Patients are right in their perception that spiritual care givers are part of a faith community, though they are hired by and working in the hospital.

Formally this is confirmed in their contract with the hospital and in their appointment by the faith community to work in the hospital. They are sent by a faith tradition not to convert people but to assist and support them in their suffering. Spiritual care givers feel called or motivated to do so out of their own faith. The trust of patients and patients' perception of spiritual care givers make many spiritual care givers feel uncomfortable with charting. That discomfort or tension has two layers. On the one hand, there is the suspected ignorance of patients around charting by spiritual care givers. They suspect that everyone charts except the spiritual care giver and the cleaning lady or cleaning man. It is no coincidence that both function as persons whom patients trust their life stories with. On the other hand, there is the constant tension about what to chart and what not to chart. Does the patient's trust, enhanced by an archaic layer of confessional confidentiality and a feeling of a free space, allow charting? This tension will increase in the near future when patients can access the charting of spiritual care givers during their stay in the hospital or from their personal computers. At this point in Flanders, patients can already access their patient files, but so far only the medical part. Spiritual care givers think they will chart differently knowing that patients can read what they write. This evolution will change the central focus from charting in order to coordinate care better to charting in order to inform the patient. Spiritual care givers also ask themselves whether patients would not be shocked if they noticed that they are charting about their visits to them. A fundamental question also arises regarding the protected documents. Will patients get access to these?

It remains important to mention that patients do not only see spiritual care givers as persons who keep confidentiality. They also see them as professionals, members of the staff in hospitals. Spiritual care givers wear badges (and sometimes also uniforms), are on call, provide worship services and rituals, are on the payroll, have a code of conduct, etc. It has also been observed that the more spiritual care givers see themselves as professionals hired by the hospital and part of the team (and not so much as being sent by a faith community), the more likely they will chart and have fewer problems with charting, also with confidential issues. Confidentiality is thus also tied to how a spiritual care giver perceives him or herself in the tension between 
being sent and being hired. Both ends of the spectrum provide a safe space: you never chart because of confidentiality or you chart everything because of your profession. In between the extremes of the spectrum lies the most interesting challenge: discerning how, when and what to chart within the reality of being hired and sent.

\section{The Language of Charting}

It is remarkable that spiritual care givers, as a professional group in Flanders, do not have just one template to chart with and do not have an agreement on the language they use. This is not just typical for Flanders, but is the case in the rest of the world too. There is not just one system spiritual care givers chart with, but many. Before electronic patient files, each spiritual care giver also had his or her own system or mode of charting. The contemporary practice of charting in different forms (ticking boxes in a checklist or narrative charting and everything in between) and using different words and concepts has the advantage of seeing what works and what doesn't. The downside is that it makes research into charting, the impact of charting and the content of contacts with patients much more complicated.

In what follows I would like to describe how I came to introduce a particular model for spiritual care in Flanders and how the language used in the model still influences charting in patient files today. Around the year 2001, I myself was a spiritual care giver in the University Hospitals in Leuven. The hospitals were being evaluated by the global management consulting firm McKinsey, which was later renamed as Accenture. The goal was clearly to enhance (financial) efficiency. The spiritual care service had to participate in all the exercises the other services had to make. We soon noticed that we did not speak the language of numbers and outcomes. How were we going to survive without losing mandates? I made contact with Larry Vandecreek, a fulltime researcher in healthcare chaplaincy in New York, and asked if he knew of any hospitals or studies where outcomes were being used. He referred me to Art Lucas, head of the spiritual care service in Barnes Jewish Hospital (BJC Health) in Saint Louis, Missouri. The team worked with an outcomeoriented model for pastoral care and had just published about it with Larry Vandecreek (Vandecreek and Lucas 2001). I ended up going to Saint Louis and working with the model for almost a year. From 2003 till 2007 I did my doctoral research on the model and underbuilt it from a theological perspective with the concept of narrative hermeneutical pastoral care (Vandenhoeck 2007). Art Lucas called the model 'The Discipline for Pastoral Care Giving'. In Flanders I introduced the model as the 'Focus Model' as it requires a particular outcome-oriented mind set from a spiritual care giver (Fig. 1).

How would you describe what spiritual care givers do? Art Lucas and his team started from their observations that spiritual care givers assess and act. Up until then, models in pastoral or spiritual care usually focused on the assessment part of the visits to patients and loved ones. The Focus Model also starts with assessment. Spiritual care givers always start with listening to the stories of patients and their 


\section{The discipline}

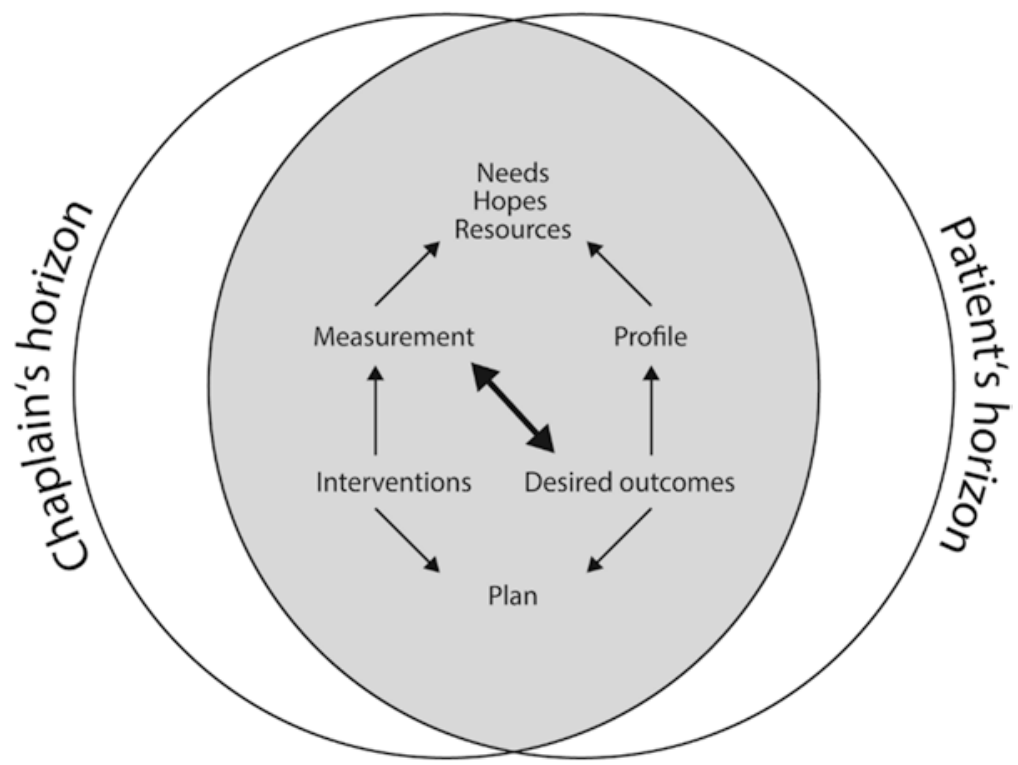

Fig. 1 The Focus Model. (Adapted with permission from Art Lucas. Copyright $@ 2004$ Art Lucas. All rights reserved)

loved ones. They listen with spiritual antennas and are particularly listening to any needs, hopes or resources patients have on a spiritual level. While they listen, they also try to discern how the community around the patient, his/her hope, his/her relation to what is sacred in life and his/her meaning giving functions in relation to being admitted in the hospital. Spiritual care givers, while listening, start to discern how they could make a difference for patients, based on their needs, hopes and resources. The differences your visit makes are outcomes of spiritual care.

An important aspect in the model is that a desired outcome needs to be shared - it needs to be congruent with the overall care plan and it needs to be desired by the patient foremost. In order to make a difference, spiritual care givers have a wide range of interventions that they have built out of their experiences. During the whole visit with the patient, spiritual care givers are focused on the feedback patients give. The verbal and non-verbal measurement of patients determines interventions and outcomes. One of the unique aspects of the model is that it starts from the observation that spiritual needs, hopes and resources (and thus interventions and outcomes) are influenced by medical pathologies. Patients with a chronic lung disease have other spiritual needs, hopes and resources than patients with heart failure. This of course is an incentive for research into shared needs, hopes, resources, interventions and outcomes by medical pathology.

One of the most important assets of the Focus Model is that it gave spiritual care givers a language to communicate within an interdisciplinary context. The language 
used in the model is a spiritual language. The concept of being a multilingual spiritual care giver was thus introduced. It was Paul Pruyser who stated that chaplains should use a theological instead of a psychological language to assess patients with (Pruyser 1976). But almost 40 years, later a broader spiritual language seems to be more understood by healthcare professionals. The language the Focus Model uses was checked with other healthcare professionals. They were asked if they thought this is what a spiritual care giver does. It is a small leap from language to charting. The model emphasizes communication in an interdisciplinary context. When I was trained to chart with the model in Saint Louis, the training started with checking boxes on a check list. After every visit I was required to go through a checklist and determine what my reason was for visiting this patient, how I would follow up, if there were any recommendations for the team and if I could name my interventions and the outcomes of the visit. Checking boxes proved to be beneficial for learning a language. Going over and over the possibilities introduced me to the language used (Fig. 2).

The next step in the learning process of charting was the challenge to no longer tick boxes but to chart in a narrative way. The model ideally advocates a functional, narrative way of charting. Narrative, as in full sentences, and functional, as in based on the difference between 'need to know' (what other care providers need to know for the best possible care) and 'nice to know' (which refers to sharing unnecessary and often confidential information). Functional, narrative charting is based on five simple principles: (1) How did I end up with this patient? (2) What is my spiritual assessment of this patient? (3) What is the outcome of my contact with the patient? (4) Which interventions did I undertake? (5) What responsibility do I take further for this patient? (accountability). The Focus Model argues for a narrative registration, because experience shows that care providers prefer to read a short piece of text instead of going over a checklist. It also advocates a functional charting that focuses on how contact with the spiritual care giver functions for the patient instead of on the content of the contact.

Two examples of functional, narrative charting:

\section{Initial visit}

Spiritual care giver visited patient $x$, referral from the attending physician. The patient expressed feeling anxious after a conversation with the doctor about her diagnosis. The spiritual care giver actively listened and explored possible future stories with the patient. The patient felt listened to and expressed feeling calmer. The spiritual care giver will visit the patient again tomorrow.

This charting describes what the spiritual care giver did without disclosing confidential information. The physician referred the patient to the spiritual care giver because she was upset after her diagnosis. When the spiritual care giver visited the patient, she expressed her fear that her husband would leave her after this diagnosis. He had been having trouble coping with her disease and had sought comfort in a relationship outside their marriage. The patient feared that this would definitely break their marriage. Nobody in her family knew of the other relationship her husband had. The patient clearly counted on the confidentiality the spiritual care giver could offer. The charting reveals what is important to the team: the patient felt anxious before the visit and calm and listened to after the visit. What was confidential 
Pt. Name

Pt. \#

Room \#

Addressograph Area

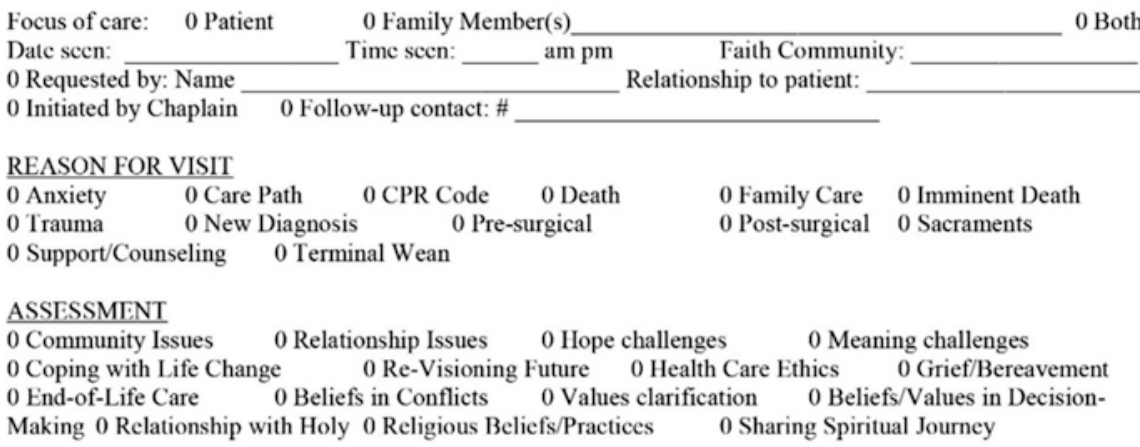

\section{PATIENT/FAMILY CONTRIBUTING OUTCOMES}

A. Outcome(s): 0 Anxiety decreased 0 Community identified/engaged 0 Grieving facilitated 0 Feels connected with The Holy 0 Values clarified 0 Felt heard 0 Hope(s) identified/clarified/restored/reconfigured 0 Sense of meaning restored 0 Sense of meaning revisioned 0 Spiritual Resources identified 0 Identified meaning/impact of life changes 0 Engaged spiritual resources 0 Experience better connection $w / t x$ team 0 Experienced supportive presence $\quad 0$ Ownership in recovery/healing $\quad 0 \mathrm{Vented} / \mathrm{shared}$ strong feelings 0 Resources liberated for healing/well-being 0 Fxperienced relief from expressing feelings

B. Progress: 0 Achieved 0 Partially Achieved/In Process 0 Not Achieved

$\underline{\mathrm{PL} \Lambda \mathrm{N}}$

\begin{tabular}{|c|c|c|c|}
\hline A. Continuing Care: $0 \mathrm{~N}$ & 0 Yes: 0 Daily & 0 Every-other-day & 0 As requested \\
\hline B. Interventions: & 0 Crisis Intervention & 0 Education Patient & 0 Educate Tx Team re \\
\hline religious/spiritual & 0 Grief Facilitation & 0 Pastoral Counseling & 0 Prayer \\
\hline 0 Sacraments/Ritual & 0 Supportive Dialogue & & \\
\hline
\end{tabular}

\section{RECOMMEND $\Lambda$ TIONS (FOR TREATMENT TEAM'S PATIENT/FAMILY CARE)}

0 End-of-Life Spiritual Care Template 0 Interdisciplinary Care Team meeting for patient/family religious rituals/practices prognosis) w patient/family

\section{Ethics Consultation $\quad 0$ Family meeting 0 Initiate DNR Discussion as appropriate 0 Provide time/privacy 0 Review Care Plan (diagnosis, condition, treatment,}

SIGNATURE

Fig. 2 Checklist. (Adapted with permission from BJC HealthCare. Copyright (C) 2001 BJC HealthCare. All rights reserved)

thus remains confidential. If the spiritual care giver felt the need to share this information with others because it was relevant for the care of the patient, it would have been good to ask the patient if this was okay. Another rule in functional, narrative charting is to stick with the facts and not to give interpretations. Only chart what the 
patient did or said: the facts. Use observations and if necessary quotes of the patient to stay as close to the patient as possible.

Follow up visit \# 3

Pre-surgery visit.

Patient expresses feelings about upcoming surgery. The cause for surgery makes patient feel like having to reconceive her future: can she continue to live alone? Spiritual caregiver explored vision of future with patient. To patient 'future' seems to be defined as 'closure' and 'letting go'. Patient asked to be blessed for surgery and upcoming future. Spiritual care giver prayed with patient.

Spiritual care giver will follow up post-surgery.

In this short functional, narrative charting, the spiritual care giver indicates some concerns for the whole of the team: the patient doubts her ability to live by herself and she has little hope. The content of the blessing and prayer remains between the patient and the spiritual care giver, but it seemed important to mention that the patient values spiritual support.

Today, the Focus Model and its language still influence the way a lot of spiritual care givers chart electronically in patient files in Flanders. I refer here to the system that was developed within the University Hospitals in Leuven and is used by every affiliated hospital. The categories of outcomes and interventions, of needs, hopes and resources are still prevalent in the charting.

\section{Points for Further Reflection}

- Charting can form a basis for policymaking and for researchers in spiritual care to carry out statistical operations and to come to an analysis of data. Policies such as care paths or protocols can be changed in order to integrate spiritual care based on charting by spiritual care givers. Charting can show that they are regularly involved in certain patient groups or in certain circumstances. Research based on charting can be executed in order to answer questions such as: Who is involved in the care for the patient? What spiritual interventions take place in visits with patients with certain diagnoses? And, is spiritual care a factor that determines the length of stay? Spiritual care givers' charting can also be used to collect statistical material to strengthen their integration and position in hospitals. Charting can show the value of spiritual care through the interventions or outcomes that are used. Based on charting, the number of mandates for spiritual care givers can be maintained or increased. Charting is therefore an important platform for further research. How can we use it further in this sense? What are the limitations and possibilities?

- The legal aspect is the big unknown and undisputed factor in this case. Who determines who has access to the electronic patient file? Is it legally permissible that spiritual care givers are allowed to chart in an electronic patient file in one hospital and not in another? Which professions are included in charting and which are not? Is there a legal basis for this, or do hospitals just have their own say? Who has access to whose entries? What needs to be written and what does 
not need to be written? Are there limits to confidentiality and what is shared confidentiality?

- The view of a patient on the spiritual care giver and the view of a professional healthcare context on the spiritual care giver can differ. For the patient, a low professional profile (the outsider who is a symbol of confidentiality and who is just present, has time and listens) for the spiritual care giver seems attractive. For other care givers and management, the opposite is often the case. They want to see a highly professional spiritual care giver who contributes to the whole of care and can communicate about his or her contribution, preferably in terms of interventions and outcomes. What does that mean for charting? What does that mean for the patient's access to the charting of spiritual care givers? It seems to be another tension where the spiritual care giver needs to balance between two extremes: non-professional and professional.

- A lot of the discussions on charting are in need of thorough theological reflection. For example: the language that is used for charting could benefit from a dialogue with theology. What language should we give to patient with spiritual issues and their loved ones to help them deal with their hospital stay? Which language can be understood by patients and healthcare professionals? Can spiritual care givers use a theological language? Or is their theological perspective a private one, the mother tongue they use among themselves but not in communication with others? And what is the value and goal of a theological reflection? What difference can the expertise of theologians make for the practice of spiritual care and charting?

\section{Recommendations}

- The most important benefit of charting for spiritual care givers is its contribution to whole person care and to the provision of the best possible spiritual care. Charting serves the best possible interdisciplinary and spiritual care. Therefore, the focus can never be on charting alone. Charting serves spiritual care and not the other way around. This discussion needs to be held on the level of paradigms and values in healthcare regarding whole person care.

- The tensions a spiritual care giver experiences regarding charting are not necessarily negative. They challenge spiritual care givers to find a balance in between extremes and serve as a constant reminder to improve the practice of spiritual care. The tension regarding confidentiality, for example, can function as a constant reminder to chart as if the patient is reading or is present.

- It is important to keep communicating with other professions in healthcare about charting and how it can serve the best possible care for patients. Other caregivers feel the same inner conflicts or doubts about charting confidential information trusted to them by patients or loved ones. They can be partners in that regard to reflect with managers and IT staff about charting forms and possibilities. Many caregivers who are not nurses or doctors do not feel that the models of charting in electronic patient files are designed for them. 


\title{
Commentary
}

\author{
Eva-Maria Faber $(\bowtie)$ \\ Theological Faculty of Chur, Chur, Switzerland \\ e-mail: eva-maria.faber@thchur.ch
}

\section{The Best Possible Spiritual Care}

It's like a refrain echoing throughout her whole article: Anne Vandenhoeck explores the best possible spiritual care as the primary goal of spiritual care givers. The best possible spiritual care involves helping and supporting patients in their suffering; it implies encounters where patients can express their needs, their sorrow and their hope and where they can entrust their stories to spiritual care givers that are willing to serve as bearers of these stories.

Anne Vandenhoeck rightly points out that charting is not merely another element in addition to these tasks of spiritual care givers but rather a means for better administering the broad spectrum of possible interventions.

The facilitating role of charting is particularly clear in connection with the task of bearing stories. Bearing stories involves remembering them - even when patients are discharged and later reappear. Charting promotes continuity in the provision of spiritual care.

Charting implies reflection that will improve future interventions. By documenting encounters with patients and by revisiting the documentation of previous encounters, spiritual care givers may discover hidden messages in what has been said and improve their understanding of how best to provide support in the future. Vandenhoeck also mentions a restorative function for spiritual care givers themselves: Charting allows carers to take a break and prevents them from carrying the burden and shadows of one patient to the next.

It is worth emphasizing this positive effect of charting on the provision of spiritual care to patients. Although the introduction of spiritual care charting was in response to the administrative need to monitor the interaction of the chaplaincy with other professions, the task of charting has in fact raised the quality of spiritual care given. Patients also stand to benefit from the greater inclusion of chaplains within interprofessional care-giving teams. For the increased visibility of the chaplaincy brings with it increased attention to the outcomes of spiritual care.

\section{Contributing to a Holistic Approach}

A crucial point concerns the question how far spiritual care givers can and should open their charting to interdisciplinary exchange. With regard to the different forms mentioned (narrative charting, ticking boxes in checklists), it seems reasonable to reserve narrative charts for personal use (protected files that help one to remember details of stories that, however, should not be shared with others or, at most, with fellow spiritual care givers). The checklists could serve as a way to give a more sparing account of the engagement of spiritual care givers.

However, the restriction of narrative charts for personal use would mean that interdisciplinary charting would be an instrument to strengthen the chaplaincy's position rather than enhance holistic care for individual patients in a hospital.

In discussions about her approach, Anne Vandenhoeck established that chaplains face a challenge concerning multilingual competence: The checklist is a tool that helps chaplains to speak a language that is understood by all healthcare givers. But at the same time it tends 
to focus on outcomes that are easily expressed in economic terms. For spiritual care givers, however, only narrative charting can assist them in bearing patients' stories. It is therefore important for them to participate in the development of the systems in order to obtain a form of documentation that corresponds to spiritual requirements. That means: only if spiritual care givers are allowed to and are willing to contribute their distinctive perspective on the patient can they take their responsibility for a holistic approach in healthcare. Only then will they promote the best possible interdisciplinary holistic care for patients.

In fact, Anne Vandenhoeck observes that, even in interdisciplinary contexts, narrative charting is more likely to be read than other forms of charting. This means: stories are a language that is also understood and appreciated from the perspective of medical agents.

\section{Confidentiality}

This is where the question of confidentiality arises that haunts the discussions about interdisciplinary charting of spiritual care. Vandenhoeck provides helpful distinctions concerning this important issue. She points to the distinction between facts and interpretation and furnishes different descriptions of the same situation: one that includes details of a patient's worries; the other to be shared without disclosing confidential aspects of his or her anxieties. Another way to meet standards of confidentiality is to focus on functional outcomes for the patient and not on possibly confidential communications. Charting will then deal more with the interventions that are intended to make a difference for patients (an inspiring wording of Vandenhoeck!) and not with information about the patient's story.

In addition to these very helpful indications it could be stimulating to reflect on the topic of the stories. If spiritual care givers are - in Vandenhoeck's beautiful description - bearers of stories, the question "What can you chart and for whom?" can be reformulated as: "What are the stories entrusted to spiritual care givers and for whom?"

Often stories are in fact entrusted confidentially to spiritual care givers. Patients may explain, or sometimes rather tentatively vocalize, how they experience their story - one that may have taken an unexpected turn as a result of a serious incident. They express their inner turmoil, their emotional perspectives on their situation, their shame. These stories are articulated in the presence of a spiritual care giver whose listening may help them to cope with a new situation. The spiritual care giver is a bearer of these stories not for others but rather a co-bearer of the story in solidarity with a person who - in telling a story - is trying to find his or her way in life. However, there may be aspects of a story that transcend the privacy and intimacy of a confident encounter. Nobody is only a patient. Whereas the medical history records the progression of an illness, the spiritual history commemorates the story and stories a person has lived and is living. Thus, spiritual care givers will often be bearers of stories not only by listening but also by reminding patients of their own stories when they become frail. Moreover, by charting some of the "public" aspects of these stories, spiritual care givers bear the stories to other members of the healthcare staff and help them to see the patient in the hospital as a whole human being.

\section{Discernment}

The best possible spiritual care is not a clearly defined measuring unit. It is a search item that depends on persons and situations and stories and, last but not least, on the feedback that patients give. This insight calls for responsibility on the part of spiritual care givers. They are called to discernment. For this reason, Anne Vandenhoeck even finds value in the tensions that spiritual care givers experience, for example in being part of the hospital team as well as belonging to the tradition of a faith community (or being sent by it). Tensions help one stay attentive - in pursuit of the best possible spiritual care. 


\section{References}

Gerkin, Charles V. 1984. The Living human document: Re-visioning pastoral counseling in a hermeneutical mode. Nashville: Abingdon.

. 1986. Widening the horizons. Pastoral responses to a fragmented society. Philadelphia: Westminster John Knox Press.

Pruyser, Paul W. 1976. The minister as diagnostician. Personal problems in pastoral perspective. Louisville: Westminster John Knox Press.

Vandecreek, Larry, and Arthur M. Lucas, eds. 2001. The discipline for pastoral care giving: Foundations for outcome oriented chaplaincy. London: Routledge.

Vandenhoeck A., Depoortere Kristiaan (sup.) 2007. De meertaligheid van de pastor in de gezondheidszorg. Resultaatgericht pastoraat in dialoog met het narratief-hermeneutisch model van C.V. Gerkin. (thesis) LXX,. 334 p.

Open Access This chapter is licensed under the terms of the Creative Commons Attribution 4.0 International License (http://creativecommons.org/licenses/by/4.0/), which permits use, sharing, adaptation, distribution and reproduction in any medium or format, as long as you give appropriate credit to the original author(s) and the source, provide a link to the Creative Commons license and indicate if changes were made.

The images or other third party material in this chapter are included in the chapter's Creative Commons license, unless indicated otherwise in a credit line to the material. If material is not included in the chapter's Creative Commons license and your intended use is not permitted by statutory regulation or exceeds the permitted use, you will need to obtain permission directly from the copyright holder.

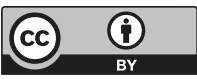

